\title{
Research on Poverty Alleviation Funds Allocation Efficiency based on the Precise Overcoming of Poverty
}

\section{- A Case Study of Sichuan}

\author{
Shengfeng Zeng ${ }^{1, a}$, Fan Yang ${ }^{2, b}$, Hao Yang ${ }^{1, c}$, Tianhui Zhuang ${ }^{1,3, d}$, Weizhong \\ Zeng ${ }^{1,3, \mathrm{e}}$ \\ ${ }^{1}$ School of Economics, Sichuan Agricultural University, Chengdu, 611130 \\ ${ }^{2}$ School of Management, Sichuan Agricultural University, Chengdu, 611130 \\ ${ }^{3}$ Southwest Center for Poverty Alleviation and Development Research, Chengdu, 611130 \\ a email, ${ }^{b}$ email, ${ }^{c}$ email, ${ }^{\mathrm{d}}$ email, ${ }^{\mathrm{e}}$ email
}

Keywords: Financial Resources; Allocation Efficiency; Accurate Poverty; DEA; Sichuan

\begin{abstract}
Based on the theoretical analysis of public finances on poverty reduction, namely poverty and poor financial investment income from the increase in viable capacity building, development opportunities and create other three output levels, the index system reflects poor financial resources allocation efficiency and the use of DEA Empirical Test of Sichuan 2011-- poor financial resources allocation efficiency in 2014. The study found that Sichuan 2011--2012 - poor financial resources allocation efficiency integrated in the active state in 2013 - 2014 by the investment of excess returns to scale caused a slight decline due to diminishing comprehensive configuration efficiency. Structural efficiency, 2011--2014 - poor financial investment allocation efficiency of the income of the poor increased levels showed a continuous downward trend; allocative efficiency for the poor feasible capacity building presents a "U" trend of the first drop after the rise of shallow inverted ; allocative efficiency and create opportunities for the poor has maintained a high level.
\end{abstract}

\section{Introduction}

Currently, the 2020 goal of building a moderately prosperous society has entered the final crucial stage. Eighth session of the Fifth Plenary Session requirements, adhere to shared development, increasing the supply of public services, increase the old revolutionary base areas, transfer payments to ethnic minority areas, border areas and poor areas, poor implementation of precision, accurate poverty alleviation project, to achieve all the people together into the overall well-off society. Poor implementation of precision, accurate poverty reduction strategies, both currently a major livelihood projects, but also a major political task. Government poverty precise, accurate poverty alleviation has no shirk responsibility, it is the nature of the government, the current government functions and characteristics of the poor of the decision (Zhengrui Jiang et al., 2011; Xu Yuanyuan, 2006). As one of the important means of government poverty reduction, expenditure proven to be effective poverty reduction (Ravallion et al, 2007; Zhang et al, 2001). Poor financial investment funds must focus on efficiency, financial resources among competing expenditure poverty alleviation project configuration is reasonable, not only directly affect the effective use of social resources, but also about whether the poor benefit from the largest financial capital, which is accurate poverty, precision out of poverty issues in the proper meaning (Li Yongyou, 2010).

\section{Poverty Index System Construction of Financial Resources Allocation Efficiency}

Eighth session of the Third Plenary Session "decision" that is the foundation and an important pillar of financial governance, scientific and taxation system is to optimize the allocation of resources, maintaining market unity, promote social justice, to achieve stability of the state system to protect (long before Zhu, 2014). According to Muslim Graves (Musgrave R A) and other public finance functions of the classic definition of (Musgrave, 1987), combined with the concrete practice of 
China's financial functions and poverty alleviation and development, financial investment path to achieve poverty reduction. First, through financial subsidies and other transfer payments to adjust income distribution, directly improve the income level of the poor, narrowing the income gap between the poor and non-poor; the second is through increased financial investment on health, education, etc., to improve the poor physical and intellectual abilities, and so improve the human capital of the poor practical capabilities, the ability to enhance the economic participation of the poor; Third, through the allocation of resources to improve transport, communications, energy, irrigation and other infrastructure and ecological environment in poor areas, enhance regional capacity for sustainable development, to create a good market trading environment, reducing regional transaction costs, shorten the distance involved in poverty-stricken areas of market transactions, to achieve a unified market, increasing opportunities and rights of the poor areas and poor people equal participation in the market, in order to achieve poverty reduction purpose. Based on the above analysis, this paper from the income level, feasible, and develop opportunities for investment in poverty reduction targets three aspects to build financial resources (Table 1).

\section{The Methods and Data}

Through literature review found that the current study used both allocative efficiency frontier production techniques to measure financial capital expenditure, namely the use of DEA constructed to measure the production possibility frontier (De et al, 1996; Chen Shih First, 2008; Afonso et al , 2010; Lionel, 2015). DEA is a linear programming method, based on a number of inputs and a number of output indicators, the number of analysis with comparable departments or units of the same type relative effectiveness evaluation, since first proposed in 1957 (Farrell made Farrell, since 1957), and in 1978 obtained from Charnes and Cooper work to promote (Charnes, 1978), it has been widely used in operations research, management science, mathematical economics and cross-disciplinary research in the field. The advantage of this method is reflected in the following aspects: First, be able to avoid linear regression equation can only consider the existence of a single variable output limitations (I swim, 2012); the second is without subjective indicators set weights, there is no need to index dimensionless processing, thus avoiding the parameters studied in functional form requires prior assumptions, parameter estimation is effective and reasonable need to be inspected and many other issues, but by a large number of actual production data point observed, based solely on objective data indicators evaluate the information, not only simplifies the evaluation process, but also enhance the results of the evaluation of the scientific nature (Yang Guoliang et al., 2013); the third is DEA method can be put into the overall efficiency of output is decomposed into technical efficiency and scale efficiency, which make up the linear regression the model assumes constant returns to scale virtual reality difficult to fit the defect (over tour, 2012). 
Table 1 Poverty Financial Allocation Efficiency Indicator System of Sichuan Province

\begin{tabular}{|c|c|c|c|}
\hline \multicolumn{2}{|c|}{ Type Indicator } & Index Name & $\begin{array}{l}\text { Direction of } \\
\text { action }\end{array}$ \\
\hline \multicolumn{2}{|c|}{ Input indicators } & Poor financial investment & + \\
\hline \multirow{25}{*}{ Output indicators } & \multirow{8}{*}{ Income level } & Per capita income levels & + \\
\hline & & Metastatic revenue share & + \\
\hline & & Per capita consumption levels & + \\
\hline & & Engel coefficient & - \\
\hline & & Urban-rural income ratio & - \\
\hline & & Rural Gini coefficient & - \\
\hline & & Poor Population & - \\
\hline & & The incidence of poverty & - \\
\hline & \multirow{6}{*}{ Capabilities } & $\begin{array}{l}\text { Percentage of administrative villages have } \\
\text { primary schools }\end{array}$ & + \\
\hline & & $\begin{array}{l}\text { Kindergarten or preschool Percentage of } \\
\text { administrative villages }\end{array}$ & + \\
\hline & & The rate of children aged 7-15 in school & + \\
\hline & & Average years of schooling & + \\
\hline & & Broadcast television households rate & + \\
\hline & & New rural cooperative medical insurance rate & + \\
\hline & \multirow{11}{*}{$\begin{array}{l}\text { Development } \\
\text { opportunities }\end{array}$} & The proportion of villages accessible by road & + \\
\hline & & $\begin{array}{l}\text { Percentage of administrative villages through } \\
\text { shuttle }\end{array}$ & + \\
\hline & & Villages of gravity on the phone & + \\
\hline & & The proportion of villages through broadband & + \\
\hline & & $\begin{array}{l}\text { The proportion of electricity production through } \\
\text { villages }\end{array}$ & + \\
\hline & & Water rate & + \\
\hline & & Agricultural land area regulation & + \\
\hline & & New land irrigated area & + \\
\hline & & Small miniature water conservancy construction & + \\
\hline & & Reforestation area & + \\
\hline & & $\begin{array}{l}\text { Forest coverage rate of growth (compared with } \\
\text { 2010) }\end{array}$ & + \\
\hline
\end{tabular}

This article will continue to use this method, for example Sichuan province, on the allocative efficiency of financial funds were poverty measurement and decomposition. Let $t$ represents time decision unit, herein, $\mathrm{t}=2011,2012,2013,2014 . \mathrm{Xt}=(\mathrm{x} 1 \mathrm{t}, \mathrm{x} 2 \mathrm{t}, \ldots \ldots . . \mathrm{xmt}), \mathrm{t}$ represents the first time the amount of investment decision-making unit, a total of $\mathrm{m}$ species, herein $\mathrm{m}=1$, that is, the amount of financial investment. $Y t=(x 1 t, x 2 t, \ldots . . ., x n t)$, it represents the amount of output $t$ th time 
decision unit, a total of $\mathrm{n}$ species. Evaluation of the $\mathrm{t}$-th time decision unit financial resources allocation efficiency of input-output constant returns to scale C2R model, variable returns to scale B2C model and non-increasing returns to scale FG model form as follows:

$$
C^{2} R\left\{\begin{array}{l}
\min \theta_{1} \\
S . t \\
\sum_{t=2011}^{2014} \lambda_{t} X_{t} \leq \theta X_{t} \\
\sum_{t=2011}^{2014} \lambda_{t} Y_{t} \geq Y_{t} \\
\lambda_{t} \geq 0 \\
t=2011,2012,2013,2014
\end{array}\right.
$$$$
B^{2} C\left\{\begin{array}{l}
\min \theta_{2} \\
S . t \\
\sum_{t=2011}^{2014} \lambda_{t} X_{t} \leq \theta X_{t} \\
\sum_{t=2011}^{2014} \lambda_{t} Y_{t} \geq Y_{t} \\
\lambda_{t} \geq 0, \sum \lambda_{t}=1 \\
t=2011,2012,2013,2014
\end{array}\right.
$$

$$
F G\left\{\begin{array}{l}
\min \theta_{4} \\
S . t \\
\sum_{t=2011}^{2014} \lambda_{t} X_{t} \leq \theta X_{t} \\
\sum_{t=2011}^{2014} \lambda_{t} Y_{t} \geq Y_{t} \\
\lambda_{2} \geq 0, \sum \lambda_{t} \leq 1 \\
t=2011,2012,2013,2014
\end{array}\right.
$$

In the above formula, $\theta$ indicates allocative efficiency; $\theta 1$ represents the synthetic allocation efficiency, given by the $\mathrm{C} 2 \mathrm{R}$ model calculations; $\theta 2$ represents technical efficiency, derived from the $\mathrm{B} 2 \mathrm{C}$ model calculations; $\theta 4$ represents the reference scale efficiency, obtained by the FG model calculations; scale efficiency

$\theta 3=\theta 1 / \theta 2$; 1t represents a unit combination coefficients, namely the decision to rebuild the t-th unit a combination ratio decision unit combinations.

Evaluation criteria poor financial resources allocation efficiency are shown in Table 2. 
Table 2 Evaluation Criteria poor capital allocation efficiency of fiscal DEA analysis

\begin{tabular}{|c|c|c|c|}
\hline Efficiency Index & \multicolumn{2}{|c|}{ Criteria } & Evaluation findings \\
\hline \multirow{2}{*}{$\theta$} & \multicolumn{2}{|c|}{$=1$} & Effective overall efficiency \\
\hline & \multicolumn{2}{|c|}{$<1$} & Effective overall efficiency \\
\hline \multirow{2}{*}{$\theta_{1}$} & \multicolumn{2}{|c|}{$=1$} & Effective technical efficiency \\
\hline & \multicolumn{2}{|c|}{$<1$} & Effective technical efficiency \\
\hline \multirow{3}{*}{$\theta_{1}$} & \multicolumn{2}{|c|}{$=1$} & Effective scale efficiency \\
\hline & \multirow{2}{*}{$<1$} & $\theta_{4}=\theta_{1}$ & $\begin{array}{l}\text { Inadequate investment caused an } \\
\text { invalid scale efficiency }\end{array}$ \\
\hline & & $\theta_{4}=\theta_{1}$ & $\begin{array}{l}\text { Invest surplus caused an invalid scale } \\
\text { efficiency }\end{array}$ \\
\hline
\end{tabular}

Poor financial resources referred to herein include special fiscal poverty alleviation funds and financial funds industry. In this paper, data from the study area when the Statistical Yearbook of Sichuan, Sichuan Province National Economic and Social Development Statistics Bulletin, authorized poverty and migration in Sichuan Bureau internal statistics, etc., will not be described hereinafter. We chose 2011--2014 As study time intervals. Such selection is based on the following considerations: 2013 Precision poverty, poverty accurate officially started, select 2011-2014, poverty can be accurate, precise poverty alleviation poverty alleviation financial resources allocation efficiency before and after the two-year comparison, find trends, analyze the reasons for the change, to better evaluate the precise poverty alleviation, poverty alleviation in poor precision utilization efficiency of fiscal funds.

\section{The Results of Analysis}

Use DEAP software, input-oriented estimates derived Sichuan 2011--2014 Poverty Reduction financial investment of the integrated output allocative efficiency, technical efficiency and scale efficiency are reported in Table 3 below. As can be seen from Table 3, Sichuan Province 2011--2012 Comprehensive Poverty Reduction financial investment allocation efficiency output is active, and 2013--2014 Comprehensive allocative efficiency presents a slight downward trend. Further analysis revealed that 2011--2014 poor financial investment in Sichuan Province technical efficiency output is always active, the "overall efficiency = technical efficiency and scale efficiency $x$ " shows that 2013--2014 Comprehensive allocative efficiency decline was mainly by the scale efficiency invalid caused, particularly, by the investment of excess leads to decreasing returns to scale caused. This phenomenon is caused by the possibility of the reason is that in 2013 with the idea put forward accurate poverty, including Sichuan, including within the country set off a 2020 building a moderately prosperous society in tackling poverty stage, financial resources at all levels of investment in the field of poverty reduction before all increased substantially compared to the central government invested poverty in Sichuan, for example, from 2011 to 8.6 million in 2014 to 33.2 billion, nearly triple. However, the efficiency of resource allocation into poverty except by some of the impact, but also by the impact of the conversion process and the output section, namely poverty reduction target which the poor themselves play an important role, only the poor have the ability and the opportunity to timely access and leverage investment in poverty alleviation , including financial resources allocation efficiency of resources, including possible poverty continues to increase. According to human capital theory, enhance the human capital of the poor is not an overnight can be improved, with a longer time lag cyclical and require long-term cultivation; at the same time, according to the laws of market development, and create opportunities for the poor external market environment nurture, we also need a more lengthy process. This may be in the case 
of poor financial investment increase, the allocation efficiency of the worse possible reasons. This is the structure behind the efficiency analysis has been confirmed once again.

Table 3 Sichuan 2011--2014 - poor financial resources integrated configuration efficiency, technical efficiency and scale efficiency

\begin{tabular}{|c|c|c|c|c|}
\hline \multirow{2}{*}{ Year } & \multirow{2}{*}{$\begin{array}{c}\text { Overall } \\
\text { efficiency }\end{array}$} & \multirow{2}{*}{$\begin{array}{c}\text { Technical } \\
\text { Efficiency }\end{array}$} & \multicolumn{2}{|c|}{ Scale efficiency } \\
\cline { 4 - 5 } & 1.000 & 1.000 & 1.000 & - \\
\hline 2011 & 1.000 & 1.000 & 1.000 & - \\
\hline 2012 & 0.990 & 1.000 & 0.990 & drs \\
\hline 2013 & 0.982 & 1.000 & 0.982 & drs \\
\hline 2014 & & & & \\
\hline
\end{tabular}

Structural efficiency poor financial capital allocation mainly to poor financial investment for the outputs, indicators are to improve the income level of the poor, the poor feasible to enhance the ability to protect the poor development opportunities in three areas covered by the output using C2R model estimates and comparison 2011--2014 poor financial investment in Sichuan Province effect on the poor income levels, practical capabilities and development opportunities, the results reported in .

Financial investment allocation efficiency increase income poverty has shown a continuous downward trend. The relationship between the overall efficiency, technical efficiency and scale efficiency shows that this is a loss because the efficiency of investment caused by excess (subject to space restrictions, the specific results not shown). The likely cause is that with poor accuracy, precision poverty work undertaken, financial resources and further increase transfer payments to the poor, but because of their own lack of poor quality and ability, it is difficult to fully rational use of financial transfer payment to obtain on the basis of secondary income wealth creation, resulting in financial investment allocation efficiency of the poor income levels continued to decline.

Financial investment for the poor development capacity allocation efficiency improvement showing variation of one fell and then picked up the trend of shallow inverted "U" shaped. Explain the possibility that, prior to the implementation of poverty alleviation precise, accurate poverty reduction strategies, aiming for more financial investment to the area (to the county to the village), pay more attention to improving the overall regional infrastructure to facilitate the poor to participate in the market economy, fair external environment. With precision poverty, poverty accurate implementation of the strategy of poverty alleviation resources into more precise targeting, start home to the people, the poor pay more attention to the cultivation of feasible capacity. However, as the foregoing analysis, human capital has a certain amount of time to enhance the periodicity and time lag, so there allocative efficiency decline phenomenon that light down the front half of the "U" shaped; It is gratifying, "U" -type movements climb from the bottom of a very short period of time, which means poverty for the poor financial investment in human capital and the ability to enhance the role of practical effect has begun to appear, both to some extent confirms Schultz (Theodore W. Schultz) in "transformation of traditional agriculture," pointed out the poor people (small farmers) are not lazy, ignorant (Schultz, 1987), they have a strong learning ability and entrepreneurial spirit, but also shows that due to the poor human capital stock less its initial investment in human capital is likely to soon have the effect of increasing returns to scale.

Allocative efficiency poor financial investment and create opportunities for the poor has maintained a high level. This means that from the outside to protect the poor to participate in market economic activities of the regional financial infrastructure investment has maintained a high allocation efficiency. Starting in 2013, the efficiency of this configuration presents a slight decline due to the possibility that, with the poor precision, precise work poverty from 2013 began, the poor investment of resources aimed at starting to focus on regional infrastructure development to poor ability to focus on practical development shift from targeting to the county to the village, home to 
more accurate to people, financial capital also began to put on a certain shift in the structure caused.

\section{Conclusions and Policy Implications}

Based on the literature review, theoretical analysis on the use of DEA Empirical Test Sichuan 2011-- poor financial resources allocation efficiency in 2014. The analysis revealed that Sichuan 2011--2012 Comprehensive Poverty Reduction financial investment allocation efficiency output is active, and 2013--2014 Comprehensive allocative efficiency presents a slight decline. Further analysis revealed that 2011--2014 poor financial investment in Sichuan Province output technical efficiency has been showing an active state, 2013--2014 Comprehensive allocative efficiency decline was mainly caused by an invalid scale efficiency, specifically, is the size of the investment due to excess caused by diminishing returns. Sichuan 2011--2014 - poor financial investment allocation efficiency to increase the poor income showing a continuous downward trend; allocative efficiency for the poor development of the ability to enhance showing a trend of the first drop of shallow inverted "U" shaped; for allocative efficiency and create opportunities for poor people has maintained a high level.

Policy implications of this paper is accurate poverty, poverty precise effect is the combined effect of multifactorial, common decision. Allocative efficiency of financial resources invested not only with financial resources, but also with financial investment during the poverty reduction target of inputs and outputs related to the conversion. A key factor in development opportunities and development capacity of the poor, and the impact of financial inputs into outputs. External development opportunities, capacity development is internal. Financial resources to play a direct transfer payments to enhance the income of the poor economy, protect their basic survival, and life needs, but also to focus on improving opportunities for poor region from the outside, the ability to enhance the development of the poor from the inside. Financial investment to increase investment in human capital of the poor, may be a short loss of efficiency, but the implications are far-reaching, it can lift people out of poverty and strengthen the endogenous dynamics of poverty, poverty will lead to independent external direction out of poverty, change "blood transfusion" for the "blood." Therefore, the Government's financial investment in poverty alleviation, should be more in the direction of lifting the poor development capacity and development opportunities tilt.

\section{References}

[1]. Amartya Sen, Wang Yu, M. poverty and famine [M]. Beijing: Commercial Press, 2014. 5-15.

[2]. Amartya Sen, Ren Ze translated Development as Freedom [M]. Beijing: China Renmin University Press, 2002. 85-98.

[3]. Chen Shiyi, Zhang Jun. Chinese local government financial expenditure efficiency study:. 1978--2005 [J]. Chinese Social Science, 2008, (4): 65-78.

[4]. Fang Jin. rural poverty and policy adjustments new stage Capabilities Perspective [J]. Economic Reform, 2011, (1): 73-78.

[5]. Fu Yong, Zhang Yan. Chinese style Decentralization and Fiscal Expenditure Structure Zhang Yan bias: the price for growth and competition [J]. Management World, 2007, (3): 4-22.

[6]. Guo Qingwang, Lu Bingyang, Zhang Deyong. Financial Expenditure Structure and Economic Growth [J]. Economic Theory and Business Management, 2003, 11 (5): 5-12.

[7]. Han Zheng. vulnerability and rural poverty [J]. Agricultural Economy, 2004, (10): 8-12.

[8]. Hu Angang, Hu Linlin, Chang Zhixiao. Chinese Economic Growth and Poverty Reduction (1978-2004) [J]. Tsinghua University: Philosophy and Social Sciences, 2007, 21 (5): 105-115.

[9]. Hua Ping. Warburg a compromise the development of ideas - Review of the World Bank "1991 Report" [J]. World Economy, 1992, (8): 81-83.

[10]. Huang Wanhua, Chen Zhu. Ability rural poverty, poverty and the rights of the peasantry curing, 
government trust - Northeast in Hubei Hubei in rural areas as an example [J]. Economic Forum, 2014, (4): 115-118.

[11]. Gu Qifeng. financial capital efficiency Poverty Research [D]. Chengdu: Southwest University of Finance and Economics, 2007. 13-14.

[12]. Li Xiangyun, Chen Jianwei. structure and performance of China's fiscal expenditure on agriculture assessment [J]. Agricultural Economy, 2010, (8): 20-25.

[13]. Li Yongyou. local funds allocation efficiency of Chinese accounting and analysis [J]. Economist, 2010, (6): 95-102.

[14]. Nexus, Jin Zhai translation. LDCs capital formation issue [M]. Beijing: Commercial Press, 1966. 6-34.

[15]. Wang Houan. Wang Yapeng. major grain producing areas of financial capital efficiency evaluation of comprehensive agricultural development [J]. Statistics and Decision, 2010, (15): 96-98.

[16]. Wang Shen. Chinese Local Financial Agriculture Investment Performance Evaluation: Based on Hierarchical expenditure Perspective [J]. Chinese Journal of Management Science, 2010, 18 (1): 26-32.

[17]. Wu Guoqi. the financial capital of performance management reform Poverty Research [D]. Beijing: Institute of Fiscal Science, 2011. 101-103.

[18]. Theodore Schultz, Liang Xiaomin. translation transformation of traditional agriculture [M]. Beijing: Commercial Press, 1987. 132-150.

[19]. Xu Yuanyuan. China Rural Poverty Government Responsibility [J]. Rural Economy, 2006, (3): 74-77.

[20]. Yan Kun. China Rural Poverty Reduction Fiscal Policy Research [M]. Beijing: China Financial and Economic Publishing House, 2008. 56-70.

[21]. Yan Kun. A public finance poverty reduction in tree Theoretical Analysis and Policy [J]. Finance and Trade Economics, 2008, (4): 61-67.

[22]. Yan Kun, a tree in the rural financial [M]. Beijing: China Social Sciences Publishing House, 2006. 27-35.

[23]. Yang Guoliang, Liu Wenbin, Zheng Haijun. data envelopment analysis (DEA) Review [J]. Journal of Systems Engineering, 2013, 28 (6): 840-860.

[24]. I swim since the tax system of public financial resources allocation efficiency measure and decomposition - Empirical Analysis Based Yunnan [J]. Economic Issues, 2012, (4): 103-110.

[25]. Zhang Gang, paragraph Che Positive Analysis on Local Fiscal Expenditure Structures and Local Economic Growth [J]. Zhejiang University (Humanities and Social Sciences), 2006, 36 (2): 88-94.

[26]. Zhang Mingming. Efficiency Evaluation of Rural Public Goods - unit test time-based DEA Method [J]. Economic Reform, 2010, (1): 107-111.

[27]. Zhang Xin public finances Outline [M]. Beijing: Economic Science Press, 1999. 1-20.

[28]. Zheng Ruiqiang, Shi Guoqing. protect the interests of poor immigrants and governmental responsibilities [J]. Chongqing University (Social Science Edition), 2011, 17 (5): 42-47.

[29]. Zhu longcai. Before repositioned under the new situation Financial Functions [J]. for Fiscal Studies, 2014, (7): 44-46.

[30]. Musgrave R A waiting Deng Ziji translated American Financial Theory and Practice [M]. Beijing: China Financial and Economic Publishing House, 1987. 5-25.

[31]. Afonso A, Schuknecht L, Tanzi V. Income distribution determinants and public spending efficiency [J]. The Journal of Economic Inequality, 2010, 8 (3):. 367-389. 
[32]. Charnes A, Cooper W W, Rhodes E. Measuring the efficiency of decision making units [J]. European journal of operational research, 1978, 2 (6):. 429-444.

[33]. De Borger B, Kerstens K. Cost efficiency of Belgian local governments:. A comparative analysis of FDH, DEA, and econometric approaches [J]. Regional Science and Urban Economics, 1996, 26 (2): 145-170.

[34]. Farrell M J. The measurement of productive efficiency [J]. Journal of the Royal Statistical Society Series A (General), 1957, 120 (3):.. 253-290.

[35]. Leibenstein H. Economic backwardness and economic growth [J]. Studies in the Theory of Economic Development, 1957, 4 (4):. 375-401.

[36]. Lionel D T. Determinants of health spending efficiency: a Tobit Panel Data Approach Based on DEA Efficiency Scores [J]. Acta Universitatis Danubius Economica, 2015, 11 (4):.. 56-69.

[37]. Nelson R R. A theory of the low-level equilibrium trap in underdeveloped economies [J]. The American Economic Review, 1956, 46 (5):. 894-908.

[38]. Ravallion M, Chen S. China's (uneven) progress against poverty [J]. Journal of development economics, 2007, 82 (1):. 1-42.

[39]. Singh R J, Huang Y. Financial Deepening, Property Rights, and Poverty: Evidence from Sub-Saharan Africa [J]. Journal of Banking and Financial Economics, 2015, 1 (3): 130-151.

[40]. Zhang T, Zou H. The growth impact of intersectoral and intergovernmental allocation of public expenditure: With applications to China and India [J]. China Economic Review, 2001, 12 (1): 58-81. 